\title{
RHYNCHOSTELE BICTONIENSIS: CAMBIOS EN ABUNDANCIA Y ÉXITO DE POLINIZACIÓN ENTRE 1992 Y 2002
}

\author{
Michael W. Dix \& Margaret A. Dix \\ Universidad del Valle de Guatemala \\ Apartado Postal 82, Guatemala, Guatemala 01901.mdix@uvg.edu.gu
}

La orquídea Rhynchostele bictoniensis ha sido estudiada por más de 25 años en las cercanías de la ciudad de Guatemala. Aunque el área se ha protegido, la población de esta especie ha ido progresivamente reduciéndose desde 1992. Una comparación entre los años 1990-1991 y 2001-2002 demuestra una reducción de $30 \%$ en el tamaño de la población y una reducción de $70 \%$ en el número de flores producidas. Solamente $2 \%$ de las flores fueron visitadas en el año 2001, comparado con $16 \%$ en el año 1990. En este año $9 \%$ de las flores fueron fecundadas, comparado con $0.25 \%$ en 2001 . Aunque por lo menos $15 \%$ de las cápsulas produjeron semillas en 1990, en 2001 ninguna llegó a la madurez. No existen plantas juveniles ni protocormos en el bosque. La abeja Bombus spp. tenía solamente una colonia conocida cercana al área de estudio en 2001, comparado con seis encontradas en 1990.

Se analizan los factores ambientales posiblemente responsables de estas diferencias y se discute la importancia relativa de los cambios climáticos observados.

Michael Dix es investigador y catedrático del Instituto de Investigaciones de la Universidad del Valle de Guatemala, con Ph.D. de Harvard University y con 36 años de docencia universitaria e investigación. Ha estudiado ecosistemas tropicales con énfasis en distribución de epífitas, especialmente orquídeas y bromelias, y reproducción ex situ de epífitas.

Margaret Dix es investigadora en la Universidad del Valle de Guatemala. Es Doctora en Biología y durante 30 años ha sido catedrática e investigadora en Guatemala. Ella realiza proyectos de investigación sobre ríos y lagos (manejo de cuencas, monitoreo, calidad de agua), control biológico de zancudos, taxonomía y ecología de la familia Orchidaceae, en especial Lycaste en Guatemala. 